\title{
Anticipated Death in New Zealand School Communities
}

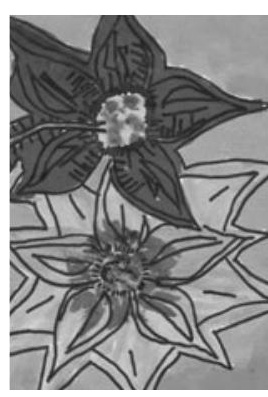

\author{
Katherine Broughton
}

\begin{abstract}
Few resources seem to be available to support school communities that have a child whose death is anticipated. The present article draws on the experiences of school staff and special education employees who have been involved in New Zealand school communities where a child was terminally ill and died. These experiences could help other school communities to provide optimal support and avoid pitfalls. Schools could use this article to develop a plan to fit their own unique situation.
\end{abstract}

\section{Practice paper}

\section{Keywords}

Crisis management, death, inclusion practices, Māori culture, parent school relationship, school role, terminal illness, traumatic incidents

\section{INTRODUCTION}

The death of a student impacts significantly on the school community. This is evident in the many resources available both nationally and internationally for helping schools respond to the unexpected death of a student. Many of these traumatic incident resources have been tailored specifically to New Zealand schools (Edwards, 2002; Meakin, Allen \& Hanifan, 1995; Ministry of Education, 2002; Rivers, Hornbrook \& Allen, 1993). This article sets the scene for ideas to guide New Zealand schools that have a student whose death is anticipated and reports findings from New Zealand teachers and Ministry of Education, Special Education staff.

\section{BACKGROUND}

\section{Anticipated death}

Anticipated death occurs when medical professionals have predicted that a person does not have much longer to live. During this time there is an opportunity to begin to come to terms with losses of the past, present and future (Gilbert, 1996; Knott \& Wild, 1986; National Cancer Institute, 2005). As the health of a child declines he or she can become vulnerable to isolation (Winston's Wish, 2003) due to a number of factors including grief (Gilbert, 1996; Knott \& Wild, 1986; National Cancer Institute, 2005) and frequent absences from school (American Society of Clinical Oncology, 2005; Holland, 2003). It is important to acknowledge the illness but not allow it to become the focus of relationships with the child. Students can help by making cards, writing letters, and drawing pictures for him or her, making a video with the child (American Society of Clinical Oncology, 2005), and visiting the home or hospital (Meakin et al., 1995). The Ministry of Education High Health Fund is available to students whose poor health means they need help accessing the curriculum and their health would be likely to deteriorate further without the support of a teacher aide (Ministry of Education, 2006).

When there is warning before a person dies it provides opportunities for loved ones to say goodbye to show the dying person how much they are cared for, and to begin to come to terms with the loss. Those involved have an opportunity to put things right before death occurs (National Cancer Institute, 2005). Loved ones begin to let go of the future with the person, yet continue to invest in the present relationship. The pain of the situation (Winston's Wish, 2003) sometimes results in people detaching themselves emotionally from the dying person while continuing to care for their physical needs (Knott \& Wild, 1986). This can make the dying person feel uncared for and abandoned (Gilbert, 1996; Holland, 2003). People are in a particularly vulnerable position when they expect a child to die and he or she takes longer than anticipated, or unexpectedly recovers (Knott \& Wild, 1986). The difficulty people experience with reinvesting emotional energy into such a relationship is well documented and is known as "The Lazarus Syndrome" (Knott \& Wild, 1986).

When a school student is expected to die, this has an impact on everyone involved. There are opportunities for the school community to support the dying child, his or her family, and friends in their grief. The anticipated death is likely to have a significant impact on some of the school staff and students as they experience grief of their own. People respond to grief differently depending on their developmental level (Rivers, 1994; Silverman, 2000; Tonkin, 1995; Worden, 1991), previous experience with losses, and skills already learned for responding to grief (Tonkin, 1995). Death can trigger strong emotions about losses that people have already experienced in their past (Alberta Department of Education, 1992; Holland, 2003; Klass, Silverman \& Nickman, 1996; Meakin et al., 1995; Tonkin, 1995).

\section{Responding to the death}

The forewarning of death does not mean there will be less pain or grief for loved ones who are faced with living without the child (Gilbert, 1996; Knott \& Wild, 1986; National Cancer Institute, 2005; Rainbow Trust, 2005; Silverman, 2000). Schools are best supported by a well constructed, established 
support plan. The main areas relevant to the anticipated death support plan are communicating the information and providing support. It is important to communicate with the family, teachers, students, and other parents about the death. Schools should maintain up-to-date contact information for students, school staff, other service providers, and support organisations in case they need to be contacted quickly (Ministry of Education, 2003a). When a death occurs, principals would usually contact the family to offer support, get consent to share information with staff, students and parents, and prepare a written statement (Dean, 2006; Ministry of Education, 2003a; Rivers, 1994; Rivers et al., 1993). The principal would then usually arrange for previously identified people to be contacted via a telephone tree including close friends of the child (Alberta Department of Education, 1992) and those whose own child or sibling had previously died (Tonkin, 1995). It is important to encourage these people to go to school as staying in a familiar routine provides support to those in grief (Meakin et al., 1995). Leaving members of the school community out can have a negative impact on the school community (Ministry of Education, 2003a).

A spokesperson for the media may be designated and should only be able to give information provided in a written statement. It may not be appropriate to discuss the incident with the media (Rivers et al., 1993). The principal may arrange relief teachers who are made available to teachers from the start of the day. A designated staff member such as the deputy principal may circulate the classrooms and monitor which teachers need time away from their classroom. The principal should convey news to staff in a school meeting as soon as possible (Rivers et al., 1993). Consideration should be given to teachers who would usually have responsibilities such as sports coaching after school. It may be appropriate for other teachers to take over these roles temporarily to reduce the demands on the staff who need extra time to be with others, or on their own (Ministry of Education, 2003b; Rivers et al., 1993). Teacher aides, under the New Zealand Educational Institute (NZEI) collective agreement (2005), are entitled to 4 weeks of pay after losing their job for any reason including the death of their student.

After school staff have been informed about the death, it would be appropriate to inform the students. A teacher or the school principal could inform the students class-by-class so that the children have opportunities to ask questions (principal, 09.03.06; teacher, 14.03.06). School staff should only tell the students what is in the written statement (Rivers et al., 1993; Ministry of Education, 2003a) and ensure that confidentiality is maintained about information that is not specifically provided by them for the school (Ministry of Education, 2003a; Rivers, 1994; Rivers et al., 1993). When the children talk about the loss it may be necessary to reduce ideas of self-blame (Ministry of Education, 2003a; Rivers et al., 1993) and increase physical closeness among the students by playing games with physical closeness such as duck, duck, goose (Rivers et al., 1993). Teachers could read the book about death after a terminal illness such as Brodie by Joy Cowley (2001) and discuss it with the class.
Maintaining routines can help prevent extra stress (Meakin et al., 1995) but avoiding talking about grief does not make it go away (Holland, 2003; Meakin et al., 1995; Perry 2006, Tonkin, 1995). In contrast, this can lead to people developing psychological, behavioural, and/or social difficulties (Alberta Department of Education, 1992; Ayyash-Abdo, 2001). Children are in a particularly vulnerable position when someone they know dies as they may not have yet developed skills to respond to grief in healthy ways (The Dougy Centre for Grieving Children and Families, 2004; Perry, 2006). Developing skills to respond appropriately to grief can benefit people at the time that they are grieving and when they experience losses in the future (Tonkin, 1995). In most cases, the support that is most effective comes from natural groupings within a community (Rivers, 1994). Teachers can help children develop skills for dealing with grief by sharing some of their own thoughts and feelings (Perry, 2006). Teachers need to be aware that normal grief reactions in children can include behaviour that is unsettled, disruptive, attention-seeking, sad, moody, inattentive, and withdrawn for a time (Rivers et al., 1993). While their academic schoolwork may also deteriorate (Holland, 2003; Perry, 2006; Tonkin, 1995), their desire to express their thoughts and feelings through art may increase (Tonkin, 1995). Some people may react immediately while others may do so weeks or months later (Rivers et al., 1993).

\section{MĀORI PERSPECTIVES ON WELLBEING}

A Māori perspective of health (or wellbeing) is considered to comprise four vital areas, te taha hinengaro ${ }^{1}$, te taha tinana ${ }^{2}$ and te taha wairua ${ }^{3}$, in the context of the family and community (te taha whānau). Known as Te Whare Tapa Whā (Durie, 1994), these areas are represented as the four walls of a house, each of which must be kept strengthened for the overall wellbeing of the person. If a person is lacking in one area the whole "house" is no longer strong. In this context, many iwi ${ }^{4}$ compare the transience of human life with the permanence of whenua ${ }^{5}$.

\section{MĀORI PERSPECTIVE: LOSS AND GRIEF}

When an anticipated death involves Māori, be sure to include tangata whenua ${ }^{6}$ to provide guidance and support for the school community's response (Ministry of Education, 2003b; Rivers et al., 1993). Māori approaches in such circumstances are guided by kaupapa Māori perspectives. Therefore, actions such as reciting a karakia ${ }^{8}$ at the beginning of a school assembly could serve to strengthen te taha wairua of those connected with the student. Likewise, expressions of awhi ${ }^{9}$ would serve to strengthen the bonds within te taha whānau ${ }^{10}$. The giving of a koha ${ }^{11}$ to the whānau such as food or money would enable te taha tinana to be strengthened (Durie, 2006; Ministry of Education, 2003b). Schools would be considered discerning if they were to maintain a putea ${ }^{12}$ for the purposes of offering koha, so as to enable the provision

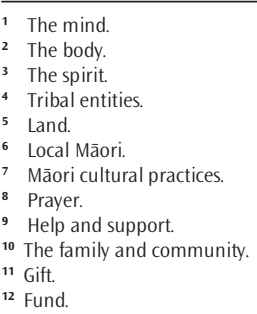

5 Land

Local Màori.

8 Praver

10 The family and community.

12 Fund. 
of food, or a money donation, to replenish whānau resources (Ministry of Education, 2003b). The overarching criterion is to abide by tikanga ${ }^{13}$ as it pertains to respective iwi. Tikanga will determine how the interactions and protocols should transpire in relation to individuals and groups of all ages.

\section{OTHER CULTURAL AND RELIGIOUS BACKGROUNDS}

In addition to discussing Māori cultural and religious backgrounds it is important to ask the family if they identify with any other culture or religion. For example, the family may be Māori on the paternal side, Tongan on the maternal side, and they may identify as being Catholic. It would be helpful to discuss cultural and religious backgrounds and beliefs with the family whether they are Māori or non-Māori, how these impact on their perspectives of death, and how they would prefer to be supported.

\section{DEVELOPMENT OF AN ANTICIPATED DEATH RESOURCE}

\section{Rationale}

Most schools have a crisis response plan in place for incidents such as sudden death, injury, or natural disasters (Ministry of Education, 2003a; special education field staff, 04.04.06). This can be used as a tool to prompt those involved to do important actions that may otherwise be forgotten about in the midst of the crisis (school staff, 09.03.06; special education field staff, 21.02.06) so that optimal support can be given to those involved (Ministry of Education, 2003a; Rivers, 1994; Rivers et al., 1993; school staff, 09.03.06). Schools adapt the crisis response resource prior to a crisis to provide the maximum support in case of the child's death. They do this by taking into consideration their school policies, the culture of their school, and supports that would be available (Ministry of Education, 2003a; school staff, 09.03.06; special education field staff, 21.03.06) and they update it as they go (school staff, 09.03.06).

The anticipated death resource is unique in that it is specifically for schools that have a child whose death is anticipated. The writer was unable to find any resources for schools that catered for this need. As with a sudden death it is important that the school has a plan to follow so that decisions can be made in advance and more effective support can be provided prior to and after the child's death (Holland, 2003). A current project involves the development of a resource based on professional literature and the experiences of New Zealand schools. This resource is intended to assist schools with providing an optimal level of support for all those involved. Consistent with the views expressed in several New Zealand traumatic incidents manuals (Meakin et al., 1995; Rivers 1994; Rivers et al., 1993), the resource will provide guidelines for schools to adapt to their own school culture and situations within it.

\section{Procedures for the development of the resource}

The following steps were taken in order to gather appropriate information for the anticipated death resource. A memo was sent out to special education staff asking them to identify potential schools where an anticipated death had occurred. They were also asked about their willingness to contribute to the resource. Several special education staff responded to the memos and provided helpful information about their own experiences in schools with anticipated death and sudden death. They gave the names of two schools that had anticipated deaths several years earlier and the principals of these schools agreed to take part in interviews for the anticipated death resource and a teacher and a teacher aide were also interviewed. School staff and special education field workers were directly involved in this study but parents and children were not. This was due to the sensitive nature of the research. During the interviews the school staff were invited to share their own experiences around the death of the student who had been expected to die and what they would suggest for other schools experiencing a similar tragedy. This was done through the following interview questions:

What did staff and students do to support and his/ her family during this difficult time?

What did staff and students do to support each other?

What did the school staff and students do in response to news of__ s death?

What guidelines would you recommend for other schools with a terminally ill student?

What other information do you think would be useful in a resource for schools responding to an anticipated death?

The interview responses were summarised and linked to relevant literature where appropriate.

Ten special education field staff (three managers, two Māori field staff, and five New Zealand European field staff from various parts of New Zealand), and four school staff (two principals, a teacher, and a teacher's aide) were involved in providing feedback on the resource, and the resource was adapted where appropriate.

\section{DISCUSSION OF EXPERIENCES OF ANTICIPATED DEATH Anticipated death}

When four school staff members were interviewed about their experiences of having a student whose death was anticipated, they emphasised the importance of including the child as much as possible in the classroom (school staff, 06.03.06, 09.03.06, 14.03.06) and playground (school staff, 06.03.06, 14.03.06). It is important to be aware of this need because as their health declines the child can become vulnerable to isolation (Winston's Wish, 2003) due to a number of factors including frequent absences from school (school staff, 14.03.06), grief (American Society of Clinical Oncology 2005; Gilbert, 1996; Knott \& Wild 1986; National Cancer Institute, 2005), feeling unwell, and looking and behaving differently (special education field staff 10.03.06). Although they acknowledged the physical condition, they did not allow it to become the focus of social interactions with the child (American Society of Clinical Oncology 2005; school staff, 09.03.06).

School staff and Ministry of Education, Special Education field staff gave a number of examples of children who continued to be included in the school community as their 
health deteriorated. For example, a child who was confined to a wheelchair due to her deteriorating health was involved in games in the playground such as "tag", where other students hopped instead of ran. In the classroom, school staff provided support for the child's changing learning and social needs through an Individual Education Plan (IEP) with the help of a teacher aide (school staff 14.03.06). Teacher aide funding may be available through the Ministry of Education High Health Fund if a student's poor health means they need help accessing the curriculum and if their health would be likely to deteriorate further without the support of a teacher aide (Ministry of Education, 2006). At a school where several students were suffering from terminal illnesses, their peers made video diaries for each of them. These were presented to the families who said that they appreciated the thought put into them and the record of their child at school (special education field staff, 28.02.06). Making videos for terminally ill children was also recommended by the American Society of Oncology (2005).

When a student's health deteriorates s/he may spend long periods of time away from school. Their classmates could continue to involve them in the classroom activities by making things specifically for them such as drawing pictures or writing letters (American Society of Oncology, 2005; school staff, 14.03.06), and by giving them work that they did as part of regular class activities, for example balloon creatures they made during art. These would have been brought to the children when they were at home or in hospital by a designated member of school staff. It may be a good idea for children to visit their ill classmate at home or in hospital, especially when $s /$ he is absent from school for long periods of time (school staff, 14.03.06). However it would be important to check with the family about the appropriateness of visits (Meakin et al., 1995) because it is important to be aware of the family's need for both support and space (school staff, 14.03.06). It may be necessary to designate a liaison person to monitor the number of visitors to prevent stress to the child and his or her family (special education field staff, 31.03.06).

It may be appropriate to inform the other children about the child's deteriorating health and how it may impact on the child. A parent (school staff, 06.03.06) or someone such as a relative, hospital staff member, or social worker could come into the classroom and give a brief explanation to the children to prepare them for changes in the way the child functions and/or looks (special education field staff, 10.03.06). For example, explaining to students that when the child gets back to school after cancer treatment he may have no hair and he may not feel as energetic as he used to. It may be appropriate to tell students that the child is not expected to live as long as they are (school staff, 14.03.06). This would need to be done after checking with the child and the child's caregivers about accuracy of information and what they want to be shared at school, respecting their need for confidentiality (Dean, 2006; Ministry of Education, 2003a; Rivers, 1994; Rivers et al., 1993). The caregivers and their child may not want other children to know that s/he is likely to die. It is not advisable to tell the school community how much longer the child is expected to live because this would set them and the child up for additional stress (Knott \& Wild, 1986). Students are likely to ask how long the child is expected to live so it would be appropriate to respond by saying something such as 'We hope Emily is comfortable and with us for as long as possible. No one knows how much longer she has to live' (special education field staff, 31.03.06)

As part of their response plan for anticipated death, schools should maintain up-to-date contact information about students, school staff, other service providers, and support organisations in case they need to be contacted quickly (Ministry of Education, 2003a). It may be appropriate to involve agencies such as the Ministry of Education; Special Education; Barnardos; tangata whenua (special education field staff, 10.03.06, 27.03.06; Ministry of Education, 2003b) and church (school staff, 14.03.06) for guidance and support (Rivers et al., 1993; school staff, 09.03.06). It may be helpful to establish a relationship between the school and a kaumātua ${ }^{14}$ who would be available to provide Māori cultural support and guidance where appropriate. Schools can do this by contacting the Ministry of Education, Special Education which could connect them with relevant people (special education field staff, 10.03.06, 27.03.06). It is important to remember that some of these people may be unavailable, so including back-up people would be helpful (Ministry of Education, 2003b). Information about other organisations can be easily accessed on the internet For example, Skylight is used by school staff and special education staff and can be found on www.skylight.org.nz.

\section{Response to death}

Although the children had been diagnosed with health problems and were not expected to survive until adulthood, their deaths came as a shock (school staff, 06.03.06, 09.03.06, 14.03.06). This is consistent with the literature which indicates that even when the death of a child is anticipated, this does not make it easier than it would have been if it was unexpected (Gilbert, 1996, Knott \& Wild, 1986; National Cancer Institute, 2005; Rainbow Trust, 2005; Silverman, 2000). The school staff who were interviewed indicated that their school's crisis response plans were used after the anticipated deaths of their students so that the family, teachers, and students would receive optimum support (school staff, 06.03.06, 09.03.06). The school principals contacted the families to offer support and prepare a written statement. They then told the teachers about the death, offered grief counselling, and provided relief teachers (school staff, 09.03.06, 14.03.06). Schools found it helpful to designate a staff member such as the deputy principal to circulate the classrooms and monitor which teachers needed time away from their students (Rivers et al., 1993; school staff, 09.03.06, 14.03.06). In one school, a special assembly was held where all students were informed about the death together (school staff, 14.03.06). In another school, students were informed class-by-class and given an opportunity to ask questions and weep (school staff, 09.03.06, 14.03.06). If students have access to mobile phones in class, this could potentially result in some children finding out about the death via text rather than from a supportive adult. In this case, informing the classes simultaneously would help reduce this risk. 
It is important to note that people respond differently to death depending on their developmental level. Letters were sent home to inform parents about the death, that it may impact on their child, and that support was available to their child at school (school staff, 09.03.06; special education field staff, 28.02.06). Teachers and their students shared happy memories of the child, and made booklets and cards (school staff, 14.03.06). It is important for schools to realise that they are the best source of their own support so it may not be appropriate or necessary to bring in counselling (special education field staff, 12.04.06).

It is important that the principal asks the parents of the deceased child about the school's presence at the funeral (school staff, 09.03.06). In the case of a tangi15 it would be important to talk to the kaumātua and find out what is appropriate and what is inappropriate (special education field staff, 27.03.06). It is important to ensure that all children going to the funeral are given parental consent to do so, and it may help to meet with the parents and children before the funeral to discuss it together. It is advisable that the children attend the funeral with their parents (school staff, 14.03.06). After the funeral, it would be helpful to invite the family to continue their relationship and involvement with the school community even if they no longer have children at the school (special education field staff, 31.03.06).

When a child dies, it is possible that some members of the school community may be overlooked during the time of grief. If the child has a taxi driver it would be important to inform them about the death. This would need to occur as soon as possible to prevent the upsetting event of going to collect the child who has died. Informing the school health nurse about the child's death would ensure that they did not come to check on their wellbeing only to find that the child had died (school staff, 14.03.06). This highlights the importance of including these people in the anticipated death resource. It would also be important to remind schools to contact people such as the caretaker, canteen staff, cleaners, and itinerant teachers. Leaving people out can have a negative impact on the school community (Ministry of Education, 2003a; school staff, 14.03.06).

If a child has regular contact with a teacher aide, this provides ample opportunity for them to develop a strong bond. If the child that they have been supporting dies, it may result in the teacher aide losing their job and as a result losing the support of the school community. In order to include the teacher aide in the school's grief process it has been recommended that the teacher aide is invited to the funeral, has access to grief counselling, and is invited back to the school to grieve with the rest of the class. In some cases the death of the child may result in financial vulnerability for the teacher aide (school staff, 14.03.06). It would be essential for schools to know that under NZEI teacher aides are entitled to four weeks of pay after losing their job for any reason including the death of their student (New Zealand Education Institute, 2005). If the death occurs during the school holidays the teacher aide is paid for the first four weeks that they would have been back at school (special education field staff, 17.03.06).
Not all schools choose to hold a memorial service or put a memorial on the school grounds because of the difficulty of gauging emotional reactions from various members of the school community (special education field staff, 20.02.06; school staff, 09.03.06, 14.03.06). Schools must negotiate a fine line between providing support and avoiding the inherent dangers of accentuating social responses to death (Dean, 2006). Several special education staff and a principal noted that giving a lot of attention to the deceased can lead to an idealistic view of death and has the potential to disrupt a whole school community (school staff, 09.03.06; special education field staff, 20.02.06). It has been recommended that if a memorial service is held at the school or a memorial is placed on the school grounds it is important to make these standard for the death of any child regardless of how they died (The Dougy Center for Grieving Children and Families, 2004; special education field staff, 20.02.06).

School staff and special education field workers were directly involved in this study but parents and children were not. This was due to the sensitive nature of the inquiry. Future investigation could include parents' and children's experiences with a student whose death was anticipated. This would offer a wider range of insights into ways of providing support for members of the school community.

In summary, a resource tailored for schools that have a child with a terminal illness would be helpful for optimising support in a school community when a child's death is anticipated and after the child dies. School staff, special education staff, and the literature indicated that an effective support plan provides specific guidelines on what information to convey and why, appropriate support for people who are grieving, and inclusion of each member of the school community.

\section{REFERENCES}

Alberta Department of Education. (1992). Bereavement and loss manual for administrators and teachers. Education Response Centre, Edmonton.

American Society of Clinical Oncology. (2005). People living with cancer. An ASCO website. Retrieved March 11, 2006, from http://www.plwc.org/plwc/Home/1.1743.00.html

Ayyash-Abdo, H. (2001). Childhood bereavement: What school psychologists need to know. School Psychology International, 22(4), 417-433.

Cowley, J. (2001). Brodie. Auckland: Scholastic New Zealand Limited.

Dean, D. (2006). Nayland Primary School crisis plan. Unpublished manual.

Durie, M. (2006). Effective interventions with young Māori: The Aotearoa reality. Unpublished Seminar Manual.

Edwards, T. (2002). Traumatic incidents "Tool Kit". A selection of useful information and sample documents to assist in the management of traumatic incidents. Unpublished manual. 
Gilbert, K. R. (1996). Anticipated losses and anticipatory grief. Retrieved February 28, 2006, from http://www. indiana. edu/ famlygrf/units/anticipated. html

Holland, J. (2003). Supporting schools with loss: 'Lost for words' in Hull. British Journal of Special Education, 30(2), 76-78.

Klass, D., Silverman, P. R., \& Nickman S. L. (1996). Continuing bonds: New understandings of grief. Washington, DC: Taylor and Francis.

Knott, J. E., \& Wild, E. (1986). Anticipatory grief and reinvestment. In T. A. Rando (Ed.), Loss and anticipatory grief (pp. 55-60). Lexington, Mass: Lexington Books.

Meakin, M., Allen, G., \& Hanifan, T. (1995). Suggestions for the presenters of in-service courses on the management of traumatic incidents. Waikato East, Special Education Service.

Ministry of Education. (2006). The school high health needs fund guidelines. The Ministry of Education, Special Education Eligibility Unit. Retrieved April 2, 2006, from http://bbb. minedu.govt. nz/index.cfm?layout=document $\&$ documentid $=5373 \&$ data $=\mid \# P 13 \_540$

Ministry of Education. (2003a). The management of traumatic incidents - Training manual. Unpublished manual.

Ministry of Education. (2003b). Aue ... he aitua. Unpublished manual.

Ministry of Education. (2002). Traumatic incident management support for schools and early childhood centres. Pamphlet.

National Cancer Institute. (2005). Supportive care statement for health professionals: Loss, grief, and bereavement Retrieved March 15, 2006, from http://www. meb. unibonn.de/cancer.gov/CDR0000062821.htmI\#REF_31

New Zealand Education Institute. (2005). Support staff in schools collective agreement January 12005 September 1 2006. Author. Retrieved April 02, 2006, from http://www.nzei.org.nz/support_staff/ pay\&conditions.htm

Perry, B. (2006). Death and loss: Helping children manage their grief. Scholastic. Retrieved March 02, 2006, from http://teacher.scholastic.com/professional/bruceperry/ death_and_loss.htm

Rainbow Trust. (2005). Rainbow Trust Children's Charity, Retrieved March 09, 2006, from http://www. rainbowtrust.

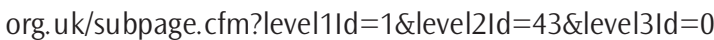

Rivers, L. (1994). Workbook: The management of traumatic incidents. Special Education Service. Unpublished manual.

Rivers, L., Hornbrook, H., \& Allen, G. (1993). Guidelines to assist in the management of traumatic incidents. Wellington, New Zealand: Special Education Service.
Skylight. (2008). Skylight: Helping young people deal with change, loss and grief. Retrieved July 28, 2008, from www.skylight.org.nz

Silverman, P. R. (2000). Never too young to know: Death in children's lives. Oxford: Oxford University Press.

The Dougy Center for Grieving Children and Families. (2004). Retrieved February 21, 2006, from http://www. dougy.org/

Tonkin, L. (1995). Change, loss and grief: A unit for primary and intermediate schools. Wellington, New Zealand: Mary Potter Hospice.

Winston's Wish. (2003). Winston's wish for grieving children and their families. Retrieved February 21, 2006, from http://winstonswish.org.uk/

Worden, J. W. (1991). Talking to children about death. Retrieved March 08, 2006, from http://www. hospicenet. org/html/talking. html

\section{AUTHOR PROFILE}

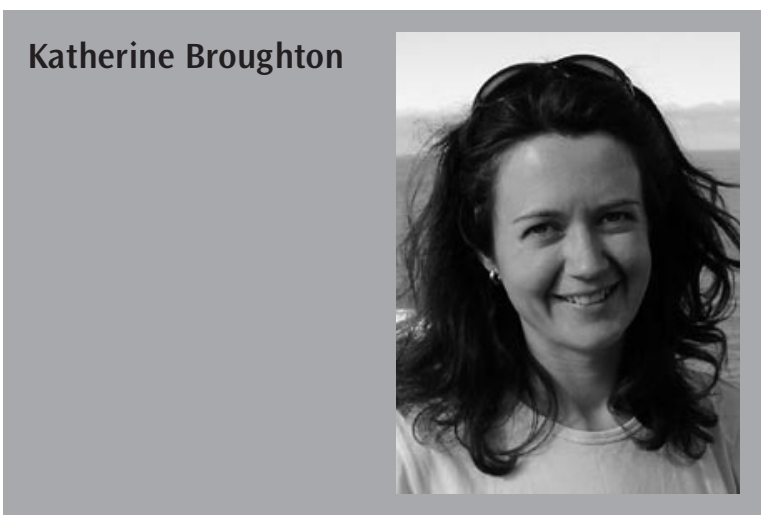

Katherine Broughton (nee Chernishov) is an Educational Psychologist who wrote this article during her internship at the Ministry of Education, Special Education, Southern Region. She wishes to thank everyone who contributed.

Email

katherinebroughton@yahoo.com 